\title{
Inherited Forms of Primary Hyperaldosteronism: New Genes, New Phenotypes and Proposition of A New Classification
}

\author{
Authors \\ Luis Gustavo Perez-Rivas ${ }^{1}$, Tracy Ann Williams ${ }^{1,2}$, Martin Reincke ${ }^{1}$
}

\author{
Affiliations \\ 1 Medizinische Klinik und Poliklinik IV, Ludwig Maximilian \\ University, Munich, Germany \\ 2 Division of Internal Medicine and Hypertension, \\ Department of Medical Sciences, University of Turin, \\ Turin, Italy
}

Key words

Primary aldosteronism, adrenal gland, aldosterone, hypertension, mineralocorticoid, genetic disease

$\begin{array}{ll}\text { received } & 16.05 .2018 \\ \text { revised } & 06.08 .2018 \\ \text { accepted } & 22.08 .2018\end{array}$

\author{
Bibliography \\ DOI https://doi.org/10.1055/a-0713-0629 \\ Published online: 10.9.2018 \\ New York \\ ISSN 0947-7349 \\ Correspondence \\ Prof. Martin Reincke \\ Medizinische Klinik und Poliklinik IV \\ Klinikum der Universität \\ LMU München
}

Exp Clin Endocrinol Diabetes 2019; 127: 93-99

(c) J. A. Barth Verlag in Georg Thieme Verlag KG Stuttgart .
Ziemssenstrasse 1

80336 München

Germany

Tel.: + 49/89/440052 100, Fax: +49/89/440054 428

martin.reincke@med.uni-muenchen.de

\begin{abstract}
Primary aldosteronism is a common cause of endocrine hypertension. It results from the excess production of aldosterone by the adrenal cortex and is related to increased morbidity and mortality. Most cases of PA are sporadic but inherited patterns of the disease have been reported in the literature. Four forms of familial hyperaldosteronism (FH-I- FH-IV) are currently recognized, and the genetic basis has been clarified in recent years. In $\mathrm{FH}-\mathrm{I}$ patients, aldosterone excess is produced by a CYP11B1/ CYP11B2 fusion gene and it is suppressed by glucocorticoid treatment. FH-II is caused by mutations in the inwardly rectifying chloride channel CLCN2. FH-III is caused by mutations in $\mathrm{KCNJ} 5$, a gene coding for an inward rectifier $\mathrm{K}^{+}$channel and mutations in the T-type calcium channel subunit CACNA1H cause FH-IV. In this review we summarize the knowledge on inherited forms of primary aldosteronism, the genetic alterations that cause them and the implications it may have for the classification. Based on current evidence, we propose the term "familial hyperaldosteronism" to refer only to inherited forms of primary aldosteronism with a known genetic basis.
\end{abstract}

\begin{abstract}
Abbreviations
PA primary aldosteronism

$\mathrm{FH}$ familial hyperaldosteronism

APA aldosterone-producing adenoma

MR mineralocorticoid receptor.
\end{abstract}

Primary aldosteronism (PA) is the clinical manifestation of a heterogeneous group of adrenal disorders that are characterized by an excessive production of aldosterone, which becomes relatively independent of the angiotensin-renin system regulation. Over time, sustained levels of aldosterone lead to increased blood pressure and elevated potassium excretion, therefore patients with PA are hypertensive, in many cases hypokalemic, and at higher risk of stroke, renal complications, metabolic and cardiovascular mortal- ity than patients with essential hypertension. Once classified as a rare disease, $\mathrm{PA}$ is now considered the most common cause of endocrine hypertension, with an estimated prevalence of about 4-6\% in the general population with hypertension and up to $10-20 \%$ in the subset of patients with resistant hypertension [1-3].

Most diagnosed cases of PA are sporadic and are mainly caused by aldosterone overproduction by both adrenal glands (bilateral adrenal hyperplasia) or by unilateral aldosterone-producing adenomas (APA). Other causes include unilateral hyperplasia and very rarely, adrenocortical carcinomas. In some cases, PA affects several members of the same family in the inherited or familial forms of hyperaldosteronism (FH). Current guidelines recognize three well established types of FH, namely FH-I to FH-III [4], however data from genetic analyses reveal a more complex situation, with at least 4 different inheritable forms of PA and possibly still more yet to be discovered. 


\section{Genes Associated With Inherited Forms of PA}

The genetics of PA has remained obscure for a long time. Although infrequent, the early onset and the heritability favored the study of familial PA as an approach to understand the pathophysiology of the more common sporadic forms. The identification of the first genetic alteration causative for a particular subtype of PA by linkage analysis on affected relatives, the chimera CYP11B1/CYP11B2[5], was an outstanding discovery but subsequent investigation quickly revealed that it was not present in sporadic forms [6,7]. The failure to find new causative genes and the introduction of next generation sequencing techniques turned the focus to sporadic patients.

Now that hundreds of APAs have been sequenced, it is well known that KCNJ5, CACNA1D, ATP1A1 and ATP2B3 genes are mutated in about $50 \%$ of adenomas (reviewed in [8] and [9]) and that ion channels and pumps exert an important role on aldosterone signaling through the control of $\mathrm{Ca}^{2+}$ influx [10]. Following the trend of next generation sequencing of sporadic cases, the study of patients with early-onset PA has uncovered that some of those genes also exert an important role in inherited forms. Thus, KCNJ5 germline mutations cause FH-III, CACNA1H mutations have been found in families with $\mathrm{FH}-\mathrm{IV}$ and de novo germline mutations in CACNA1D have been reported in patients with early onset of $P A$, seizures and neurologic abnormalities (PASNA). In addition, two recent studies in patients with early-onset PA have shown mutations in CLCN2 associated with FH-II. - Table 1 summarizes the genes associated with PA and the main clinical features and $\mathbf{D i g}$. 1 depicts the molecular mechanisms.

\section{CYP11B1/CYP11B2 chimera: familial hyperaldosteronism type I ( $\mathrm{FH}-\mathrm{I})$}

FH-1 was first reported in 1966 by Sutherland and colleagues [11]. They reported two hypertensive relatives, a father and a son, with a condition that mimicked the symptoms of sporadic PA (increased aldosterone, low renin activity and hypokalemia) but with the particularity of suppression of aldosterone production by a $2 \mathrm{mg} /$ day dexamethasone treatment. Thus $\mathrm{FH}-\mathrm{I}$ is often referred to as gluco- corticoid-remediable aldosteronism (GRA). The basis of the glucocorticoid suppression was discovered in 1992, after linkage analysis identified the genetic cause as a chimeric fusion on chromosome 8 containing an unequal recombination between the highly homologous genes CYP11B1 (11- $\beta$-hydroxylase) and CYP11B2 (aldosterone synthase) [5]. The exact point of cross-over can be different in each reported family but always contains the promoter and the first exons of CYP11B1 and most of the coding region of CYP11B2, resulting in an enzyme with aldosterone synthase activity with

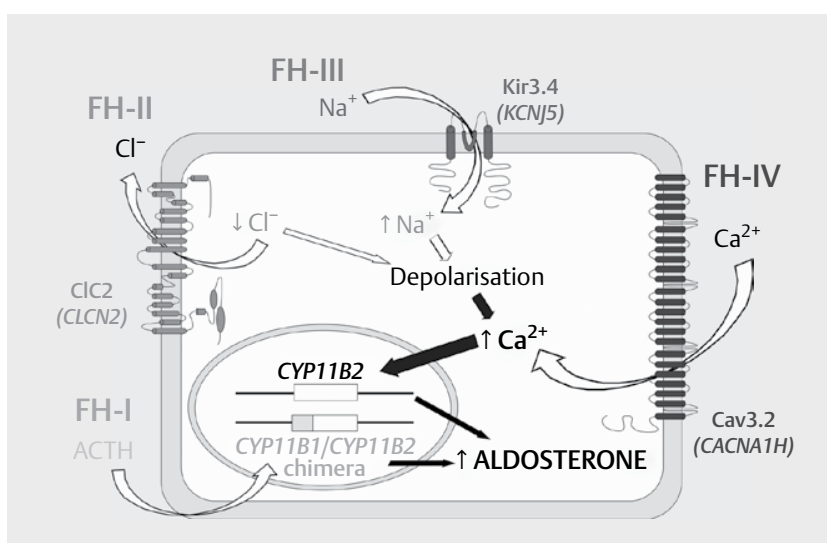

- Fig. 1 Genetic causes of familial hyperaldosteronism. Summary of the known molecular mechanisms that lead to familial hyperaldosteronism types I to IV. FH-I is produced by an asymmetrical recombination between CYP11B1 and CYP11B2, resulting in the expression of a chimeric enzyme under the control of ACTH stimulation. FH-II is caused by germline mutations in the chloride channel CLCN2 that decrease intracellular $\mathrm{Cl}^{-}$. $\mathrm{FH}-\mathrm{III}$ is produced by germline mutations in KCNJ5 that affect the selectivity of the channel, allowing $\mathrm{Na}^{+}$ conductance. Both reduction of intracellular $\mathrm{Cl}^{-}$and increase in $\mathrm{Na}^{+}$ cause plasma membrane depolarization and open voltage-gated $\mathrm{Ca}^{2+}$ channels, elevating cytosolic $\mathrm{Ca}^{2+}$. FH-IV is caused by germline mutations in CACNA1H that facilitate $\mathrm{Ca}^{2+}$ entry. In all cases, increase of intracellular $\mathrm{Ca}^{2+}$ triggers CYP11B2 transcription and aldosterone synthesis.

- Table 1 Germline mutations associated with primary aldosteronism.

\begin{tabular}{|c|c|c|c|c|}
\hline Germline alteration & Biological effect & Clinical manifestation & Treatment & Pattern of heritability \\
\hline $\begin{array}{l}\text { CYP11B1/CYP11B2 } \\
\text { chimeric fusions }\end{array}$ & $\begin{array}{l}\text { Aldosterone synthase } \\
\text { inducible by ACTH } \\
\text { stimulation } \\
\end{array}$ & $\begin{array}{l}\text { Glucocorticoid-suppressible } \\
\text { hyperaldosteronism (FH-I) }\end{array}$ & $\begin{array}{l}\text { Low dose of dexamethasone, MR } \\
\text { antagonists as second line }\end{array}$ & Autosomal dominant \\
\hline CLCN2 mutations & Increased $\mathrm{Cl}^{-}$efflux & FH-II & MR antagonists & $\begin{array}{l}\text { Autosomal dominant, } \\
\text { incomplete penetrance }\end{array}$ \\
\hline KCNJ5 mutations & $\begin{array}{l}\text { Reduced } \mathrm{K}^{+} \text {selectivity } \\
\text { and increased } \mathrm{Na}^{+} \\
\text {influx }\end{array}$ & $\mathrm{FH}-\mathrm{III}$ & $\begin{array}{l}\text { MR antagonist if mild, adrenalec- } \\
\text { tomy if severe }\end{array}$ & Autosomal dominant \\
\hline CACNA1H mutations & Increased $\mathrm{Ca}_{2}{ }^{+}$entry & FH-IV & $\begin{array}{l}\text { Not standardized. No control } \\
\text { observed under spironolactone } \\
\text { treatment or unilateral adrenalec- } \\
\text { tomy }\end{array}$ & $\begin{array}{l}\text { Autosomal dominant, low } \\
\text { penetrance }\end{array}$ \\
\hline CACNA1D mutations & Increased $\mathrm{Ca}_{2}{ }^{+}$entry & $\begin{array}{l}\text { PA associated with seizures and } \\
\text { neurological abnormalities } \\
\text { (PASNA) }\end{array}$ & $\begin{array}{l}\text { MR antagonist, adrenalectomy if } \\
\text { lateralized }\end{array}$ & $\begin{array}{l}\text { Autosomal dominant not } \\
\text { likely to be inherited }\end{array}$ \\
\hline ARMC5 mutations & $\begin{array}{l}\text { Loss of ARMC5 } \\
\text { expression/function }\end{array}$ & $\begin{array}{l}\text { Apparently sporadic, possible } \\
\text { predisposition to PA }\end{array}$ & Data not available & $\begin{array}{l}\text { Autosomal dominant, } \\
\text { incomplete penetrance }\end{array}$ \\
\hline
\end{tabular}


expression under the control of the adrenocorticotropic hormone (ACTH) instead of angiotensin II and potassium. As a consequence, aldosterone synthase is expressed in the zona fasciculata rather than in the zona glomerulosa, resulting in the ectopic production of aldosterone and the production of the hybrid steroids 18-oxocortisol and 18-hydroxycortisol [5, 12].

$\mathrm{FH}-\mathrm{I}$ is considered as a rare subgroup of PA that represents less than $1 \%$ of all cases, increasing to $3 \%$ in children with hypertension [13-15]. It is characterized by the development of bilateral adrenal hyperplasia, occasionally adrenal nodules, with variable clinical and biochemical features $[14,16]$. FH-I follows an autosomal dominant inheritance pattern and is generally associated with early onset severe hypertension and an increased risk of stroke; however, different degrees of severity have been reported, including cases of mild hypertension and normotensive individuals [16-18].

The Endocrine Society guideline recommends testing for $\mathrm{FH}-\mathrm{I}$ in patients with an early onset of PA ( $<20$ years old) and in those with a familial occurrence of PA or stroke at a young age ( $<40$ years old) [4]. The correct diagnosis is clinically relevant because aldosterone excess can be controlled successfully through glucocorticoid therapy [19]. Prior to the existence of targeted molecular tests, the diagnosis was made through clinical and biochemical evaluation. Dexamethasone suppression of aldosterone and levels of hybrid steroids were used to establish a diagnosis of FH-I [20,21] until the introduction of techniques to specifically detect the presence of the CYP11B1/CYP11B2 chimeric gene either by Southern blotting or by the recommended technique employing a long-chain PCR amplification [4, 21-23].

In patients with $\mathrm{FH}-\mathrm{I}$ aldosterone production is abrogated under glucocorticoid treatment, and partial suppression of ACTH is enough to correct the hypertension associated with FH-I. Accordingly, low doses of dexamethasone are recommended to achieve normotension whilst preventing undesired cushingoid features [19]. Mineralocorticoid receptor antagonists (spironolactone or eplerenone) can be used as a second line of therapy to block possible non-genomic effects of aldosterone on target organs, or in children to avoid possible side effects of dexamethasone treatment [24]. If target blood pressure levels are not reached by low dose dexamethasone, additional standard antihypertensive medication can be added (i.e. calcium antagonists, beta-blockers).

\section{CLCN2: familial hyperaldosteronism type II (FH-II)}

FH-II was first described by Gordon et al. in 1991, a year before the genetic cause of $\mathrm{FH}$-I was published. They described 6 relatives from 3 independent affected families who presented with PA caused by either APA or BAH and a lack of suppression of aldosterone production by fludrocortisone or dexamethasone [25]. Several families were reported by the same group shortly thereafter $[26,27]$.

Until very recently, the genetic cause of $\mathrm{FH}$-II remained elusive. Early targeted genetic studies showed a lack of mutations on genes related to steroidogenic production or tumorigenesis, such as CYP11B2, the angiotensin receptor AT1R or TP53. Later on, genetic linkage analysis of non-related families highlighted a locus at chromosome 7p22 that segregated with the disease in some families, but not in all cohorts [28-30]. However both targeted sequencing of different genes in that region as well as next-genera- tion sequencing of the complete locus failed to find mutations [29, 31-33]. Scholl and colleagues analyzed the genomic DNA by exome sequencing of three members from one of the FH-II families described by Stowasser et al. in 1992 [27]. The authors identified a germline mutation in the gene CLCN2 that segregated with the disease. This variant, p.Arg172GIn, was confirmed subsequently in five additional family members, four of them with aldosterone-to-renin ratio suggestive of PA [34]. Because the discovery family was one of the first families diagnosed with FH-II, Scholl et al. proposed the use of that term only for inherited PA due to CLCN2 mutations [34]. The authors also reported the same mutation in three additional unrelated individuals, as well as rare germline CLCN2 variants (p.Met22Lys, p.Tyr26Asn, p.Lys362del and Ser865Arg, with allele frequencies below $10^{-5}$ ) in four additional unrelated patients [34]. Simultaneously, Fernandes-Rosa and colleagues identified another germline CLCN2 mutation in a 9-yearsold patient by exome-sequencing sequencing of genomic DNA from 12 patients with young-onset hypertension and PA. In that case, p.Gly24Asp was a de novo mutation. Two additional variants were found in two cases from a cohort of 100 patients with idiopathic bilateral adrenal hyperplasia (p.Arg66GIn and p.Pro48Arg, with minor allele frequencies of $3 \times 10^{-5}$ and $1.7 \times 10^{-4}$, respectively) [35]. Both studies showed that CLCN2 mutations were related to PA diagnosed at early age and absent in patients with essential hypertension [34, 35].

CLCN2 gene is located in chromosome 3q27 and encodes the inwardly rectifying chloride channel $\mathrm{ClC2}$, a member of the $\mathrm{CLC}$ voltage-gated $\mathrm{Cl}^{-}$channels family. $\mathrm{ClC2}$ is broadly expressed in mammalian cells, especially in brain, gut, kidney, heart and liver [36]. Mutations inactivating CLCN2 cause leukodystrophy, in some cases with azoospermia, and $\mathrm{Clcn} 2$ knockout mice also develop early postnatal retinal degeneration [37-39]. Scholl et al. and Fernandes-Rosa et al. have shown that $\mathrm{ClC2}$ is also expressed in the adrenal gland. Furthermore, germline mutations that associate with $\mathrm{PA}$ result in gain of function of the $\mathrm{Cl}^{-}$channel, causing an efflux of $\mathrm{Cl}^{-}$ions that leads to the depolarization of the plasma membrane, the consequent opening of voltage-gated $\mathrm{Ca}^{2+}$ channels, the accumulation of cytosolic $\mathrm{Ca}^{2+}$ and the activation of CYP11B2 transcription $[34,35]$.

Before the recent discovery of CLCN2 mutations, screening for $\mathrm{FH}$-Il was based on the diagnosis of PA in at least two first-degree members of the same family and the absence of known germline mutations. Thus, this familial form was thought to be the most prevalent, representing about $3-6 \%$ of all PA cases [11, 54]. Nevertheless, Korah and Scholl pointed out that this estimation may be misleading: considering the prevalence of hypertension in the general population (about $30 \%$ ) and the PA prevalence in the general population with hypertension (about $5 \%$ ), the probability for an index case to have at least a first-degree relative with PA just by chance is $\sim 5.9 \%$ [40]. Accordingly, it is likely that some of the described FH-II families were in fact coincidental cases of sporadic idiopathic PA. This observation may explain, at least partially, the apparent heterogeneity reported in previous studies. To avoid confusion, and to base the classification on a simple and transparent genetic basis similar to other genetic diseases, we propose to use the term "familial hyperaldosteronism" only when an inherited genetic cause is established. 
Following this reasoning, the number of true $\mathrm{FH}$-II families is probably much lower than previously reported. In their studies, Scholl et al. and Fernandes-Rosa et al. identified CLCN2 mutations in about $10 \%$ of cases with young-onset PA without known germline mutations and $2 \%$ with bilateral adrenal hyperplasia [34, 35] suggesting a lower frequency than previous estimates. Further efforts are needed to determine the actual prevalence of FH-II.

\section{KCNJ5: familial hyperaldosteronism type III (FH-III)}

FH-III was described by Geller et al. in three family members, a father and his two young daughters, who developed hyperaldosteronism with hypokalemia and severe hypertension at very early age, together with marked bilateral adrenal enlargement. High levels of the hybrid steroids 18-oxocortisol and 18-hydroxycortisol were detected in urine samples but the disorder was distinguishable from $\mathrm{FH}-\mathrm{I}$ by the glucocorticoid resistance of the hyperaldosteronism and the lack of suppression of aldosterone production on dexamethasone suppression testing. Hypertension and hypokalemia were refractory to medical therapy and disease control was achieved only after bilateral adrenalectomy [41]. Careful examination of the adrenals revealed disorganized zonation, a reduction in the thickness of the zona glomerulosa, an enlarged zona fasciculata and the presence of cells that co-express enzymes which are usually expressed in distinct zones, such as CYP11B1 and CYP11B2 and also CYP17 and CYP11B2. The co-expression of CYP17 and CYP11B2 is the likely basis for the production of hybrid steroids [12,41,42].

It was not until 2011 that the genetic etiology of FH-III was clarified. By means of exome sequencing, Choi et al. identified a heterozygous germline mutation located on chromosome 11q24 in the patients reported by Geller and colleagues, as well as in sporadic cases of PA [43]. The affected gene was KCNJ5, which codes for the $\mathrm{G}$-protein-activated inward rectifier $\mathrm{K}^{+}$channel 4 (Kir3.4). This protein forms homo- and heterotetramers with other Kir family members to constitute the functional G-protein-activated inwardly rectifying potassium channel, which contributes to the control of membrane polarity in the zona glomerulosa [44]. The mutation identified in Geller's cases (p.Thr158Ala) was associated with a loss in $\mathrm{K}^{+}$selectivity and an increased influx of $\mathrm{Na}^{+}$into the cytoplasm, leading to membrane depolarization and the elevation of intracelIular $\mathrm{Ca}^{2+}$ levels, which ultimately triggers aldosterone production through the activation of $\mathrm{Ca}^{2+}$-related signaling pathways [45].

Since the link between inherited PA and KCNJ5, several familial cases with different mutations in that gene have been published, mostly in or next to the selectivity filter [46-51], and the term FH-III is used for familial cases with PA due to germline KCNJ5 mutations, regardless of the phenotype. Indeed, the clinical features of the affected cases vary all along the PA spectrum, from mild and treatment-responding forms to severe PA with progressive disease, including symptoms mimicking diabetes insipidus and a recent report showing development of Cushing's syndrome in one patient with FH-III [50]. This variability seems to be dependent on the type of the grounding KCNJ5 mutations, among other factors[46]. Thus, p.Gly151Glu mutations seem to associate with a milder phenotype and stable disease $[46,49]$, while p.Gly151Arg, p.Thr158Ala, p.lle157Ser and p.Tyr152Cys mutations relate to a more severe hyperaldosteronism [52]. Other infrequent germline alterations of KCNJ5 (some of them de novo) and a rare non-synonymous SNP (rs7102584) have been described. The mutation p.Glu145Gln affects a salt bridge close to the selectivity filter, while mutations p.Arg52His, p.Glu246Lys, p.Gly247Arg and the SNP Glu282GIn were located elsewhere in the protein $[53,54]$. Except of the p.Gly247Arg, those variants altered channel functionality and increased aldosterone production compared with the wild-type protein.

The prevalence of FH-III has not been established systematically but it is estimated to be present in $<1 \%$ of all PA cases [47]. The Endocrine Society guideline recommends testing for $\mathrm{FH}$-III by sequencing peripheral blood for mutations in $\mathrm{KCNJ} 5$ in those patients with a very early onset of PA [4]. Because of the variety of presentations, treatment for $\mathrm{FH}$-III depends on the severity of the disease. Milder cases can be well controlled with spironolactone, while adrenalectomy is currently the best option to treat resistant forms successfully [52].

\section{CACNA1H: familial hyperaldosteronism type IV (FH-IV)}

FH-IV was reported by Scholl and coworkers in a cohort of 40 patients diagnosed with PA in early childhood (at age 10 years or below) and without mutations in any common known PA genes. By whole exome sequencing analysis, a recurrent mutation in the gene CACNA1H was identified in five unrelated patients, four males and one female [55]. Shortly thereafter Daniil et al. reported the presence of different mutations in the same gene in two unrelated individuals who were diagnosed originally with $\mathrm{FH}$-II, as well as an adult male case with a de novo mutation and an adult female patient with an APA and a germline mutation in the same gene [56]. Patients showed no apparent signs of seizures, cardiac arrhythmia or muscular or neurological alterations that have been commonly linked to other disorders caused by CACNA1H germline mutations or by another $\mathrm{Ca}^{2+}$ channel subunit, CACNA1D[57], although one of the patients was diagnosed with minor mental retardation and multiplex developmental disorder [56]. So far, eight families with FH-IV have been described.

The gene CACNA1 $\mathrm{H}$ is located on chromosome 16 and encodes the T-type (low voltage activated) calcium channel subunit Cav3.2. This protein is expressed in the zona glomerulosa [55, 57] and, as other Cav3 family members, is activated by small depolarizing changes in the membrane potential [58]. Germline CACNA1H mutations have been associated with several diseases including epilepsy, autism and amyotrophic lateral sclerosis [59-61]. In their studies, Scholl et al. and Daniil et al. reported six index cases with germline mutations affecting the residue Met1549, four cases with an inherited p.Met1549Val substitution, one with a de novo p.Met1549Val and one with a de novo p.Met1549lle [55, 56]. This residue is located in the transmembrane segment S6 of the repeat domain III of Cav3.2, forming a conserved methionine-phenylalanine-valine (MFV) tripeptide motif that controls channel inactivation [62]. Functional experiments have demonstrated that mutations in Met1549 result in a decrease in the inactivation of Cav3.2 compared with the wild-type protein. As a consequence, the channel remains open longer with an increase in $\mathrm{Ca}^{2+}$ influx, which activates the expression of CYP11B2 and other steroidogenic genes $[55,56,63]$. Noteworthy, treatment with a T-type calcium channel blocker abrogated the aberrant CYP11B2 activation and aldosterone production in HAC15 cells overexpressing Cav3.2 p.Met- 
1549 Val mutant channels, which indicates that drugs of this class could be useful in the treatment of patients with FH-IV [63].

In their study, Daniil et al. reported 3 additional variants: p.Ser196Leu, located in the voltage sensor region on the transmembrane segment $\mathrm{S} 4$ of the repeat domain I of Cav3.2, in a male patient and his sister; p.Pro2083Leu, located in the C-terminal cytoplasmic domain, in another index case and his brother; and a de novo p.Val1951Glu, also located in the C-terminal domain, in a patient with an APA (no familial history available). All mutations altered Cav3.2 function and enhanced aldosterone production to a greater or a lesser degree [56].

Although further studies are needed, available data suggests that FH-IV may be a rare form of FH. It follows an autosomal dominant pattern of heritability but with reduced penetrance, particularly in adults. Indeed, some family members with mutations in p.Met1549 were affected with resistant hypertension and PA and others displayed milder or even normotensive phenotype, suggesting that other factors, such as genetic modifiers, somatic mosaicism or the age of the patient, could restrain the gene defect [55]. The type and location of the mutation may also play a role in the pathophysiology of $\mathrm{FH}-\mathrm{IV}$, resembling what has been described for KCNJ5 [46]. This fact could also explain the differences on disease presentation among the index cases: some of them were florid cases of PA at their early childhood but without evidence of adrenal hyperplasia; while other patients were diagnosed in their adulthood, nodularity was detected bilaterally in one patient and an APA was diagnosed in another case $[55,56]$.

\section{Other Germline Mutations Described in Patients With PA}

Although not considered established causes of $\mathrm{FH}$, it is worth mentioning that germline mutations in CACNA1D and ARMC5 have been reported in patients with $P A$.

CACNA1D codes for Cav1.3, an L-type (high-voltage activated) $\mathrm{Ca}^{2+}$ channel subunit and is recurrently mutated in about $10 \%$ of sporadic APAs. Most sporadic alterations cause gain of function and lead to an increase of $\mathrm{Ca}^{2+}$ influx and the consequent overproduction of aldosterone [57]. Recently, Scholl and coworkers identified two de novo mutations in two unrelated cases diagnosed with PASNA (PA associated with seizures and neurological abnormalities) [57]. Although the severe comorbidities of affected individuals make the heritability of PASNA very unlikely, it is tempting to speculate that other CACNA1D mutations that cause a milder phenotype could be involved in a still not described familial form of PA, in the same way that has been proposed for $\mathrm{KCNJ} 5$ in $\mathrm{FH}$-III.

ARMC5 encodes an apoptosis regulator that belongs to the armadillo/ $\beta$-catenin-like repeat superfamily. Inactivating mutations in ARMC5 have been reported in both sporadic and inherited primary bilateral macronodular hyperplasia, an adrenocortical disease associated with cortisol excess [64-66]. Mutated ARMC5 promotes cell survival and cortisol production in vitro $[64,65]$. Interestingly, germline ARMC 5 variants have been identified in patients with apparent sporadic cases of PA $[67,68]$, suggesting a possible inherited predisposition for nodule formation prior to the hormonal-producing phenotype. Nevertheless, the deleterious effect of those mutations is still quite unclear, as most variants are predicted to be unlikely pathogenic [69]. Thus, further studies must confirm or refuse the possible role of ARMC5 germline mutations in the etiology of PA.

\section{New Genes, New Phenotypes - We Need a New Classification!}

In the recent years, our knowledge on inherited forms of PA has progressed substantially [8, 70]. FH classification has evolved from two clinically distinct forms ( $\mathrm{FH}-\mathrm{I}$ and $\mathrm{FH}-\mathrm{II}$ ) described in the previous Endocrine Society guideline [71] to at least four genetically defined types in which patients are grouped based on the presence of causative mutations (FH-I/CYP11B1/B2 chimera, FH-II/CLCN2, $\mathrm{FH}-\mathrm{III} / \mathrm{KCNJ} 5$ and FH-IV/CACNA1H). Despite substantial scientific advances, some questions remain unanswered. Firstly, the clinical heterogeneity within groups of $\mathrm{FH}$ related to variable disease presentation and incomplete penetrance suggest a possible modulation of genetic causes by non-genetic factors. This hypothesis could explain why relatives with germline mutations are apparently asymptomatic. Secondly, the prevalence of FH-II and FH-IV families is still uncertain. Evidence suggests that the frequency of CLCN2 and CACNA1H mutations is low. Thus, extensive studies are needed to determine the actual prevalence and the clinical relevance of these subtypes. Lastly, it must be elucidated whether apparent familial cases without known mutations truly follow inherited patterns of PA. Further next-generation sequencing studies will gain insight into the molecular causes of PA and probably contribute to the establishment of new FH types. Misclassification of sporadic PA cases as $\mathrm{FH}$ should be avoided. For that reason, we discourage the use of non-genetic criteria for the screening and classification of $\mathrm{FH}$ and propose the term "familial hyperaldosteronism" only to be used when known germline mutations are detected.

\section{Funding}

This work was supported by the European Research Council (ERC) under the European Union's Horizon 2020 research and innovation programme (grant agreement No [694913] to MR) and by the Deutsche Forschungsgemeinschaft (DFG) (within the CRC/Transregio 205/1 "The Adrenal: Central Relay in Health and Disease" to MR and TAW; and grant RE 752/20-1 to MR) and the Else Kröner-Fresenius Stiftung in support of the German Conns Registry-Else-Kröner Hyperaldosteronism Registry (2013_A182 and 2015_A171 to MR). L.G.P-R is supported by a fellowship from the People Programme (Marie Curie Actions) of the European Union's Seventh Framework Programme (FP7/2007-2013) under REA grant agreement no. 608765.

\section{Conflict of Interest}

No conflict of interest has been declared by the authors. 


\section{References}

[1] Rossi GP, Bernini G, Caliumi C et al. A prospective study of the prevalence of primary aldosteronism in 1,125 hypertensive patients. J Am Coll Cardiol 2006; 48: 2293-2300

[2] Mosso L, Carvajal C, González A et al. Primary aldosteronism and hypertensive disease. Hypertension 2003; 42: 161-165

[3] Monticone S, Burrello J, Tizzani D et al. Prevalence and clinical manifestations of primary aldosteronism encountered in primary care practice. J Am Coll Cardiol 2017; 69: 1811-1820

[4] Funder JW, Carey RM, Mantero F et al. The management of primary aldosteronism: case detection, diagnosis, and treatment: An endocrine society clinical practice guideline. J Clin Endocrinol Metab 2016; 101: 1889-1916

[5] Lifton RP, Dluhy RG, Powers M et al. A chimaeric 11 beta-hydroxylase/ aldosterone synthase gene causes glucocorticoid-remediable aldosteronism and human hypertension. Nature 1992; 355: 262-265

[6] Pallauf A, Schirpenbach C, Zwermann O et al. The prevalence of familial hyperaldosteronism in apparently sporadic primary aldosteronism in Germany: A single center experience. Horm Metab Res 2012; 44: $215-220$

[7] Carroll J, Dluhy R, Fallo F et al. Aldosterone-producing adenomas do not contain glucocorticoid-remediable aldosteronism chimeric gene duplications. J Clin Endocrinol Metab 1996; 81: 4310-4312

[8] Prada ETA, Burrello J, Reincke M et al. Old and new concepts in the molecular pathogenesis of primary aldosteronism. Hypertens (Dallas, Tex 1979) 2017; 70: 875-881

[9] Zennaro MC, Boulkroun S, Fernandes-Rosa FL. An update on novel mechanisms of primary aldosteronism. J Endocrinol 2015; 224: R63-R77

[10] Gomez-Sanchez CE. Channels and pumps in aldosterone-producing adenomas. J Clin Endocrinol Metab 2014; 99: 1152-1156

[11] Sutherland DJA, Ruse JL, Laidlaw JC. Hypertension, increased aldosterone secretion and low plasma renin activity relieved by dexamethasone. Can Med Assoc J 1966; 95: 1109-1119

[12] Lenders JWM, Williams TA, Reincke $M$ et al. 18-Oxocortisol and 18-hydroxycortisol: Is there clinical utility of these steroids? Eur J Endocrinol 2018; 178: R1-R9

[13] Mulatero P, Tizzani D, Viola A et al. Prevalence and characteristics of familial hyperaldosteronism: the PATOGEN study (Primary Aldosteronism in TOrino-GENetic forms). Hypertension 2011; 58: 797-803

[14] Aglony M, Martínez-Aguayo A, Carvajal CA et al. Frequency of familial hyperaldosteronism type 1 in a hypertensive pediatric population: Clinical and biochemical presentation. Hypertens (Dallas, Tex 1979) 2011; 57: 1117-1121

[15] Pizzolo F, Trabetti E, Guarini P et al. Glucocorticoid remediable aldosteronism (GRA) screening in hypertensive patients from a primary care setting. J Hum Hypertens 2005; 19: 325-327

[16] Fallo F, Pilon C, Williams TA et al. Coexistence of different phenotypes in a family with glucocorticoid-remediable aldosteronism. J Hum Hypertens 2004; 18: 47-51

[17] Mulatero P, Cella SMDi, Williams TA et al. Glucocorticoid remediable aldosteronism: Low morbidity and mortality in a four-generation Italian pedigree. J Clin Endocrinol Metab 2002; 87: 3187-3191

[18] Stowasser M, Huggard PR, Rossetti TR et al. Biochemical evidence of aldosterone overproduction and abnormal regulation in normotensive individuals with familial hyperaldosteronism type I. J Clin Endocrinol Metab 1999; 84: 4031-4036

[19] Stowasser M, Bachmann AW, Huggard PR et al. Treatment of familial hyperaldosteronism type I: Only partial suppression of adrenocorticotropin required to correct hypertension. J Clin Endocrinol Metab 2000; 85: 3313-3318
[20] Rich GM, Ulick S, Cook S et al. Glucocorticoid-remediable aldosteronism in a large kindred: clinical spectrum and diagnosis using a characteristic biochemical phenotype. Ann Intern Med 1992; 116: 813-820

[21] Litchfield WR, New MI, Coolidge $C$ et al. Evaluation of the dexamethasone suppression test for the diagnosis of glucocorticoid-remediable aldosteronism. J Clin Endocrinol Metab 1997; 82: 3570-3573

[22] Jonsson JR, Klemm SA, Tunny T] et al. A new genetic test for familial hyperaldosteronism type I aids in the detection of curable hypertension. Biochem Biophys Res Commun 1995; 207: 565-571

[23] Mulatero P, Veglio F, Pilon C et al. Diagnosis of glucocorticoid-remediable aldosteronism in primary aldosteronism: aldosterone response to dexamethasone and long polymerase chain reaction for chimeric gene. J Clin Endocrinol Metab 1998; 83: 2573-2575

[24] Quack I, Vonend O, Rump LC. Familial hyperaldosteronism IIII. Horm Metab Res 2010; 42: 424-428

[25] Gordon RD, Stowasser M, Tunny T] et al. Clinical and pathological diversity of primary aldosteronism, including a new familial variety. Clin Exp Pharmacol Physiol 1991; 18: 283-286

[26] Stowasser M, Gordon RD, Tunny TJ et al. Primary aldosteronism: implications of a new familial variety. J Hypertens Suppl 1991; 9: S264-S265

[27] Stowasser M, Gordon RD, Tunny T] et al. Familial hyperaldosteronism type ii: Five families with a new variety of primary aldosteronism. Clin Exp Pharmacol Physiol 1992; 19: 319-322

[28] So A, Duffy DL, Gordon RD et al. Familial hyperaldosteronism type II is linked to the chromosome 7p22 region but also shows predicted heterogeneity. J Hypertens 2005; 23: 1477-1484

[29] Carss KJ, Stowasser M, Gordon RD et al. Further study of chromosome 7 p22 to identify the molecular basis of familial hyperaldosteronism type II. J Hum Hypertens 2011; 25: 560-564

[30] Fallo F, Pilon C, Barzon L et al. Retention of heterozygosity at chromosome 7p22 and 11q13 in aldosterone-producing tumours of patients with familial hyperaldosteronism not remediable by glucocorticoids. J Hum Hypertens 2004; 18: 829-830

[31] Jeske YWA, So A, Kelemen L et al. Examination of chromosome 7p22 candidate genes RBaK, PMS2 and GNA12 in familial hyperaldosteronism type II. Clin Exp Pharmacol Physiol 2008; 35: 380-385

[32] Elphinstone MS, Gordon RD, So A et al. Genomic structure of the human gene for protein kinase $A$ regulatory subunit R1-beta (PRKAR1B) on 7p22: No evidence for mutations in familial hyperaldosteronism type II in a large affected kindred. Clin Endocrinol (Oxf) 2004; 61: 716-723

[33] Stowasser M, Gordon RD. Primary Aldosteronism: Changing Definitions and New Concepts of Physiology and Pathophysiology Both Inside and Outside the Kidney. Physiol Rev 2016; 96: 1327-1384

[34] Scholl UI, Stölting G, Schewe J et al. CLCN2 chloride channel mutations in familial hyperaldosteronism type II. Nat Genet 2018; 50: 349-354

[35] Fernandes-Rosa FL, Daniil G, Orozco IJ et al. A gain-of-function mutation in the CLCN2 chloride channel gene causes primary aldosteronism. Nat Genet 2018; 1-7

[36] Thiemann A, Gründer S, Pusch M et al. A chloride channel widely expressed in epithelial and non-epithelial cells. Nature 1992; 356 : 57-60

[37] Di Bella D, Pareyson D, Savoiardo M et al. Subclinical leukodystrophy and infertility in a man with a novel homozygous CLCN2 mutation. Neurology 2014; 83: 1217-1218

[38] Depienne C, Bugiani M, Dupuits C et al. Brain white matter oedema due to $\mathrm{CIC}-2$ chloride channel deficiency: An observational analytical study. Lancet Neurol 2013; 12: 659-668

[39] Bösl MR, Stein V, Hübner C et al. Male germ cells and photoreceptors, both dependent on close cell-cell interactions, degenerate upon ClC-2 $\mathrm{Cl}(-)$ channel disruption. EMBO J 2001; 20: 1289-1299 
[40] Korah HE, Scholl UI. An update on familial hyperaldosteronism. Horm Metab Res 2015; 47: 941-946

[41] Geller DS, Zhang J, Wisgerhof MV et al. A novel form of human mendelian hypertension featuring nonglucocorticoid- remediable aldosteronism. J Clin Endocrinol Metab 2008; 93: 3117-3123

[42] Gomez-Sanchez CE, Qi X, Gomez-Sanchez EP et al. Disordered zonal and cellular CYP11B2 enzyme expression in familial hyperaldosteronism type 3. Mol Cell Endocrinol 2017; 439: 74-80

[43] Choi M, Scholl UI, Yue P et al. $\mathrm{K}+$ channel mutations in adrenal aldosterone-producing adenomas and hereditary hypertension. Science 2011; 331: 768-772

[44] Velarde-Miranda C, Gomez-Sanchez EP, Gomez-Sanchez CE. Regulation of aldosterone biosynthesis by the Kir3.4 (KCNJ5) potassium channel. Clin Exp Pharmacol Physiol 2013; 40: 895-901

[45] Oki K, Plonczynski MW, Lam ML et al. Potassium channel mutant KCNJ5 T158A expression in HAC-15 cells increases aldosterone synthesis. Endocrinology 2012; 153: 1774-1782

[46] Scholl UI, Nelson-Williams C, Yue P et al. Hypertension with or without adrenal hyperplasia due to different inherited mutations in the potassium channel KCNJ5. Proc Natl Acad Sci USA 2012; 109: 2533-2538

[47] Mulatero P, Tauber P, Zennaro MC et al. KCNJ5 mutations in European families with nonglucocorticoid remediable familial hyperaldosteronism. Hypertension 2012; 59: 235-240

[48] Monticone S, Hattangady NG, Penton D et al. A novel Y152C KCNJ5 mutation responsible for familial hyperaldosteronism type III. J Clin Endocrinol Metab 2013; 98: 1861-1865

[49] Adachi M, Muroya K, Asakura Y et al. Discordant genotype-phenotype correlation in familial hyperaldosteronism type III with KCNJ5 gene mutation: A patient report and review of the literature. Horm Res Paediatr 2014; 82: 138-142

[50] Tong A, Liu G, Wang F et al. A novel phenotype of familial hyperaldosteronism type III: Concurrence of aldosteronism and cushing's syndrome. J Clin Endocrinol Metab 2016; 101: 4290-4297

[51] Mussa A, Camilla R, Monticone S et al. Polyuric-polydipsic syndrome in a pediatric case of non-glucocorticoid remediable familial hyperaldosteronism. Endocr ] 2012; 59: 497-502

[52] Monticone S, Tetti M, Burrello J et al. Familial hyperaldosteronism type III. J Hum Hypertens 2017; 31: 776-781

[53] Monticone S, Bandulik S, Stindl J et al. A case of severe hyperaldosteronism caused by a de novo mutation affecting a critical salt bridge Kir3.4 residue. J Clin Endocrinol Metab 2015; 100: E114-E118

[54] Murthy M, Xu S, Massimo G et al. Role for germline mutations and a rare coding single nucleotide polymorphism within the KCNJ5 potassium channel in a large cohort of sporadic cases of primary aldosteronism. Hypertension 2014; 63: 783-789
[55] Scholl UI, Stölting G, Nelson-Williams C et al. Recurrent gain of function mutation in calcium channel CACNA1H causes early-onset hypertension with primary aldosteronism. Elife 2015; 4: e06315

[56] Daniil G, Fernandes-Rosa FL, Chemin J et al. CACNA1H mutations are associated with different forms of primary aldosteronism. EBioMedicine 2016; 13: 225-236

[57] Scholl UI, Goh G, Stölting G et al. Somatic and germline CACNA1D calcium channel mutations in aldosterone-producing adenomas and primary aldosteronism. Nat Genet 2013; 45: 1050-1054

[58] Talavera K, Nilius B. Biophysics and structure-function relationship of T-type Ca2 + channels. Cell Calcium 2006; 40: 97-114

[59] Steinberg KM, Yu B, Koboldt DC et al. Exome sequencing of caseunaffected-parents trios reveals recessive and de novo genetic variants in sporadic ALS. Sci Rep 2015; 5: 1-8

[60] Splawski I, Yoo DS, Stotz SC et al. CACNA1H mutations in autism spectrum disorders. J Biol Chem 2006; 281: 22085-22091

[61] Chen Y, Lu J, Pan $\mathrm{H}$ et al. Association between genetic variation of CACNA1H and childhood absence epilepsy. Ann Neurol 2003; 54: 239-243

[62] Marksteiner R, Schurr P, Berjukow $S$ et al. Inactivation determinants in segment IIIS6 of $\mathrm{Ca}(\mathrm{v}) 3.1$. J Physiol 2001; 537: 27-34

[63] Reimer EN, Walenda G, Seidel E et al. CACNA1HM1549V mutant calcium channel causes autonomous aldosterone production in HAC15 cells and is inhibited by mibefradil. Endocrinology 2016; 157: 3016-3022

[64] Assié G, Libé R, Espiard S et al. ARMC5 mutations in macronodular adrenal hyperplasia with Cushing's syndrome. N Engl J Med 2013; 369 : 2105-2114

[65] Espiard S, Drougat L, Libé R et al. ARMC5 mutations in a large cohort of primary macronodular adrenal hyperplasia: Clinical and functional consequences. J Clin Endocrinol Metab 2015; 100: E926-E935

[66] Gagliardi L, Schreiber AW, Hahn CN et al. ARMC5 mutations are common in familial bilateral macronodular adrenal hyperplasia. J Clin Endocrinol Metab 2014; 99: E1784-E1792

[67] Rhayem Y, Pérez-Rivas LG, Dietz A et al. PRKACA somatic mutations are rare findings in aldosterone-producing adenomas. J Clin Endocrinol Metab 2016; 101: 3010-3017

[68] Zilbermint M, Xekouki P, Faucz FR et al. Primary aldosteronism and ARMC5 variants. J Clin Endocrinol Metab 2015; 100: E900-E909

[69] Mulatero P, Schiavi F, Williams TA et al. ARMC5 mutation analysis in patients with primary aldosteronism and bilateral adrenal lesions. J Hum Hypertens 2016; 30: 374-378

[70] Asbach E, Williams TA, Reincke M. Recent developments in primary aldosteronism. Exp Clin Endocrinol Diabetes 2016; 124: 335-341

[71] Funder JW, Carey RM, Fardella C et al. Case detection, diagnosis, and treatment of patients with primary aldosteronism: An endocrine society clinical practice guideline. J Clin Endocrinol Metab 2008; 93: 3266-3281 